- Regular Articles-

\title{
Doripenem Pharmacokinetics in Critically Ill Patients Receiving Continuous Hemodiafiltration (CHDF)
}

\author{
Seigo HidaKa, ${ }^{*}$ Koji Goto, Satoshi Hagiwara, Hideo IwaSAKa, and Takayuki Noguchi \\ Department of Anesthesiology and Intensive Care, Faculty of Medicine, Oita University, \\ 1-1 Idaigaoka-Hasamamachi, Yufu, Oita 879-5593, Japan
}

(Received May 8, 2009; Accepted September 25, 2009)

\begin{abstract}
Objectives of the prospective, open-label study were to investigate pharmacokinetics of doripenem and determine appropriate doripenem regimens during continuous hemodiafiltration (CHDF) in critically ill patients with renal failure (creatinine clearance $<30 \mathrm{ml} / \mathrm{min}$ ) in the intensive care unit at a university hospital in Japan. Six patients received intravenous (IV) administration of $250 \mathrm{mg}$ of doripenem every 12 or 24 hours during CHDF (dialysis rate, $500 \mathrm{ml} / \mathrm{h}$; hemofiltration rate, $300 \mathrm{ml} / \mathrm{h}$ ) via a polysulfone hemofilter. Doripenem concentrations in pre- and post-membrane blood (plasma) samples collected at specified times during one dosing interval were measured in order to calculate pharmacokinetic parameters and clearance via hemodiafiltration. Mean half-life ( \pm standard deviation) of doripenem was $7.9 \pm 3.7$ hours. Total body clearance of doripenem was $58.0 \pm 12.7 \mathrm{ml} / \mathrm{min}$, including clearance of $13.5 \pm 1.6 \mathrm{ml} / \mathrm{min}$ via CHDF. An IV dose of $250 \mathrm{mg}$ of doripenem every 12 hours during CHDF provided adequate plasma concentrations for critically ill patients with renal failure, without resulting in accumulation upon steady-state. Thus, under the conditions tested, CHDF appeared to have little effect on doripenem clearance. Therefore, the blood level of doripenem can be satisfactorily controlled by adjustment of doripenem dose and dosing interval, in accordance with residual renal function in patients receiving CHDF.
\end{abstract}

Key words_ acute renal failure; antibiotic; hemodiafiltration; pharmacology

\section{INTRODUCTION}

As continuous hemodiafiltration (CHDF) has frequently been used as an indispensable treatment in critically ill patients with renal failure, ${ }^{1)}$ the indications for CHDF use have expanded. Currently, $\mathrm{CHDF}$ is employed in various conditions such as renal failure, acute hepatic failure, congestive heart failure, severe acute pancreatitis, and sepsis ${ }^{2-4)}$ as an important means of assisting failed or dysfunctional organs.

A problem requiring special attention during $\mathrm{CHDF}$, however, is that the pharmacokinetics (PK) of medications may be markedly affected by elimination through filtration and dialysis, making it difficult to establish appropriate levels of drug in the bloodstream. ${ }^{5-7)}$ If a drug is retained in vivo, it may cause new occurrences of organ failure, whereas if drug levels in the blood do not reach an effective range, the apparent efficacy of the drug may be insufficient. Inadequate doses of antimicrobial agents can result in development of drug-resistant pathogens. When caring for severely ill patients, use of ap-

\footnotetext{
*e-mail: sehidaka@med.oita-u.ac.jp
}

propriate antimicrobial agents active against the pathogen and adequate treatment at the correct dose levels are essential for improving the rates of survival. ${ }^{8)}$ Therefore, clarification of the PK of antibiotics during CHDF will be clinically beneficial.

Doripenem (Finibax ${ }^{\circledR}$; Shionogi \& Co., Ltd., Osaka, Japan), a new antibiotic of the carbapenem family, was approved in Japan (in July, 2005) and the USA (in October, 2007). As doripenem has a broad antibacterial spectrum and excellent antibacterial activity, it is expected to improve the outcome of treatment of previously intractable infections. Because doripenem is excreted primarily via the kidneys, adequate care is needed when using doripenem in patients with compromised renal function. We previously demonstrated in a pilot study with a limited sample size that a single dose of doripenem did not affect its concentration in serum during CHDF. ${ }^{20)}$ In the present study, we examined the effect of repeated doses of doripenem on its concentration in serum during CHDF. Furthermore, the PK of doripenem was examined in patients treated with CHDF in order to obtain useful information for designing safer, more effective methods of using doripenem. 


\section{MATERIALS AND METHODS}

Patients Prior to the start of the investigation, the study was authorized by the Medical Research Ethics Committee of Oita University Hospital in Japan. Informed consent was obtained in writing from each study participant or his/her relatives.

Participants included 6 patients who received treatment with doripenem during CHDF for acute kidney injury in the intensive care unit (ICU) at Oita University Hospital between November, 2006 and March, 2008. Patients receiving sodium valproate (for which concomitant use of doripenem is prohibited) and patients with compromised hepatic function were excluded from this study.

Patient Characteristics Of the 6 critically ill patients included in this study, none had been treated with doripenem prior to enrollment. All patients completed the scheduled period of PK sampling.

Demographic and medical characteristics of individual patients are shown in Table 1. All patients had severe renal dysfunction, with creatinine clearances (Ccr, an indicator of residual renal function) that ranged from 3.7 to $15.0 \mathrm{ml} / \mathrm{min}$ (mean $=9.02 \mathrm{ml}$ / $\mathrm{min})$. Residual diuresis was not extensive in any patient during the study period.

Doripenem Administration and Collection of Blood Samples Doripenem (250 mg; Shionogi \& Co., Ltd., Japan) was dissolved in $20 \mathrm{ml}$ of physiological saline solution and administered intravenously by drip infusion for $1 \mathrm{~h} /$ session. Each of three patients (ID 1-3) received a single dose of $250 \mathrm{mg}$ of doripenem. Blood samples were collected from indwelling arterial cannula in heparinized tubes before doripenem treatment (at $0 \mathrm{~h}$ ), at $1 \mathrm{~h}$ (just prior to the end of the infusion period), and at 2, 4, 6, 8, 12 and $24 \mathrm{~h}$ after the onset of infusion.
Another three patients (ID 4-6) each received 250 $\mathrm{mg}$ of doripenem every $12 \mathrm{~h}$ for at least 4 days. On the first day of therapy, arterial blood samples were obtained immediately before infusion, at $1 \mathrm{~h}$ (just prior to the end of the infusion period), and at 2, 4, 7, and $12 \mathrm{~h}$ after the onset of infusion. Arterial blood sampling was repeated on day 4 (at the subsequent 7 th dose), after steady-state concentrations of doripenem nominally had been achieved. At $4 \mathrm{~h}$ following onset of infusion, venous blood samples were taken from the sampling port located after the dialyzer.

At each point of sampling, approximately $2 \mathrm{ml}$ of blood was collected into a heparinized sampling tube and centrifuged immediately at $3000 \mathrm{rpm}$ for $15 \mathrm{~min}$ at $4^{\circ} \mathrm{C}$. The resultant supernatant containing approximately $1 \mathrm{ml}$ of plasma was transferred to a polypropylene tube and immediately frozen at $-80^{\circ} \mathrm{C}$ for storage until later analysis.

Pharmacokinetics (PK) of Doripenem Doripenem levels in human plasma were determined by a validated high-performance liquid chromatography (HPLC; Shimadzu 10 A series) method, performed by Mitsubishi Chemical Medience Corporation (Tokyo, Japan). Samples were subjected to solidphase extraction (Bond Elute C18). Eluates $(90 \mu \mathrm{l})$ were injected into the HPLC system combined with an octadecyl silica column (Cosmosil 5C18-MS, 5 $\mu \mathrm{m}, 4.6 \mathrm{~mm}$ I.D. $\times 250 \mathrm{~mm})$ and UV detector $(300$ $\mathrm{nm})$. The mobile phase of $20 \%$ methanol and $80 \%$ of $50 \mathrm{mmol} / 1$ phosphate buffer ( $\mathrm{pH}$ 6.2) containing 5 $\mathrm{mmol} / \mathrm{l}$ tetrabutylammonium phosphate was delivered isocratically at a flow rate of $0.7 \mathrm{ml} / \mathrm{min}$. Doripenem levels in human plasma were also determined by liquid chromatography/tandem mass spectrometry (LC/MS/MS; MDS SCIEX API 4000), performed by Mitsubishi Chemical Medience Corporation. Doripenem-13C5d2 was added to thawed

Table 1. Patient Characteristics

\begin{tabular}{ccccclcr}
\hline \hline Patient & Gender & $\begin{array}{c}\text { Age } \\
(\text { years })\end{array}$ & $\begin{array}{c}\text { Weight } \\
(\mathrm{kg})\end{array}$ & $\begin{array}{c}\mathrm{Ccr} a) \\
(\mathrm{ml} / \mathrm{min})\end{array}$ & \multicolumn{1}{c}{ Admission diagnosis } & APACHE II $^{b)}$ & SOFA $^{c}$ \\
\hline ID-1 & M & 63 & 52 & 6.7 & ileus, sepsis & 26 \\
ID-2 & M & 74 & 56 & 12.0 & ruptured abdominal aneurysm & 26 \\
ID-3 & F & 59 & 52 & 9.8 & pneumonia, sepsis & 23 & 13 \\
ID-4 & F & 68 & 62 & 6.9 & pyoderma gangrenosum, sepsis & 12 \\
ID-5 & M & 56 & 73 & 3.7 & aortic and mitral valve replacement & 17 & 12 \\
ID-6 & F & 84 & 52 & 15.0 & dissecting thoracic aortic aneurysm & 26 \\
\hline
\end{tabular}

a) Ccr: creatinine clearance; $b$ ) APACHE II: Acute Physiology and Chronic Health Evaluation II; $c$ ) SOFA: Sequential Organ Failure Assessment. Data from patients ID-1 and ID-2 were reported in our previous study. ${ }^{20)}$ 
plasma samples $(20 \mu \mathrm{l})$ as internal standards. Samples were subjected to protein precipitation using acetonitrile, mixed, and centrifuged. Supernatants $(100 \mu \mathrm{l})$ were injected into the LC/MS/MS system combined with an octadecyl silica column (Unison US-C18, $5 \mu \mathrm{m}, 4.6 \mathrm{~mm}$ I.D. $\times 50 \mathrm{~mm})$ and a TurboionSpray interface, which was set to the positive multiple reactions monitoring mode. The first mobile phase consisted of water $/ 20 \mathrm{mmol} / 1$ ammonium formate/formic acid (95:5:0.1, v/v/v) and second mobile phase consisted of acetonitrile/water $/ 20$ $\mathrm{mmol} / \mathrm{l}$ ammonium formate/formic acid (80:15 : $5: 0.1, \mathrm{v} / \mathrm{v} / \mathrm{v} / \mathrm{v})$. The first and second mobile phases were delivered by step gradient $(100: 0 \rightarrow 75: 25 \rightarrow$ $0: 100)$ at a flow rate of $0.6 \mathrm{ml} / \mathrm{min}$. The lower limits of quantification for these assays were $0.20 \mu \mathrm{g}$ of doripenem $/ \mathrm{ml}$. Non-compartmental PK analysis of doripenem was performed. From the data on plasma level of doripenem during the elimination phase, the elimination rate constant $\left(\lambda_{\mathrm{Z}}\right)$ and the half-life $\left(\mathrm{T}_{1 / 2}\right)$ of doripenem during the elimination phase were calculated. Using the trapezoidal method, we calculated the area under the plasma concentration-time curve (AUC) and the distribution volume at steady-state (Vdss). From the dose level of doripenem and the AUC, total clearance $\left(\mathrm{CL}_{\text {Total }}=\right.$ dose $\left./ \mathrm{AUC}\right)$ was determined. $\mathrm{CHDF}$ clearance $\left(\mathrm{CL}_{\mathrm{CHDF}}\right)$ was calculated from the following equation:9)

$$
\mathrm{CL}_{\mathrm{CHDF}}=\mathrm{Q}_{\mathrm{B}} \times(1-\mathrm{Hct}) \times\left(\mathrm{C}_{\mathrm{in}}-\mathrm{C}_{\text {out }}\right) / \mathrm{C}_{\mathrm{in}} \text {, }
$$

where $Q_{B}$ is the blood flow rate, Hct is the hematocrit level, $C_{\text {in }}$ is the plasma concentration of doripenem before the hemofilter, and $\mathrm{C}_{\text {out }}$ is the plasma concentration of doripenem after the hemofilter. Plasma concentrations of doripenem in plasma at the end of drug administration were considered to be the maximum plasma concentration $\left(\mathrm{C}_{\max }\right)$ of doripenem.

CHDF In the present study, a polysulfone hemofilter with a membrane surface area of $1.0 \mathrm{~m}^{2}$ (HEMOFEEL $^{\circledR}$ SH-1.0, Toray Medical, Inc., Japan) was used for hemopurification. CHDF was performed with a blood flow rate $\left(\mathrm{Q}_{\mathrm{B}}\right)$ of $100 \mathrm{ml} /$ $\min$, a dialysate flow rate $\left(\mathrm{Q}_{\mathrm{D}}\right)$ of $500 \mathrm{ml} / \mathrm{h}$, and a filtration flow rate $\left(\mathrm{Q}_{\mathrm{F}}\right)$ of $300 \mathrm{ml} / \mathrm{h}$. Sublood-BS ${ }^{\circledR}$ (Fuso Pharmacy, Inc., Japan) was used as a dialysate and also served as substitution fluid infused postdilusionally. During CHDF, nafamostat mesylate was serially administered at a rate of $20-30 \mathrm{mg} / \mathrm{h}$ to avoid coagulation within the circuit.

Statistical Analysis Results were expressed as the mean \pm standard deviation (S.D.). Statistical analysis was performed with StatView V software (Abacus Concepts, Berkeley, CA) .

\section{RESULTS}

\section{Plasma Concentration Profiles of Doripenem}

Patients ID1 and ID2 participated in our previous study. ${ }^{20)}$ Figure 1 illustrates the time course of concentration of doripenem in plasma after a single dose in 3 patients (ID 1-3) or after the first dose in the other 3 patients (ID 4-6). In all patients in our study, plasma concentrations of doripenem decreased in a bi-exponential manner.

Figure 2 shows the mean ( \pm standard deviation) of plasma concentrations of doripenem over time in each patient (ID 1-6) in our study, as well as the plasma concentrations of doripenem in patients with various degrees of renal impairment reported by Uehara and colleagues in a previous clinical study. ${ }^{10)}$ According to the report by Uehara et al., the Ccr values in two patients in the $\mathrm{Ccr}<30 \mathrm{~min} / \mathrm{ml}$ group were 17.8 and $24.2 \mathrm{ml} / \mathrm{min}$ (mean: $21.0 \mathrm{ml} / \mathrm{min}$ ). In patients ID 1-3 in the present study, the Ccr averaged $9.5 \mathrm{ml} /$ min and was thus lower than that in the patients examined by Uehara et al. Furthermore, even when patients ID 1-6 in the current study underwent $\mathrm{CHDF}$, the level of doripenem in plasma was low for a prolonged period of time.

Figure 3 illustrates data on the plasma doripenem concentration-time for the initial dose administered

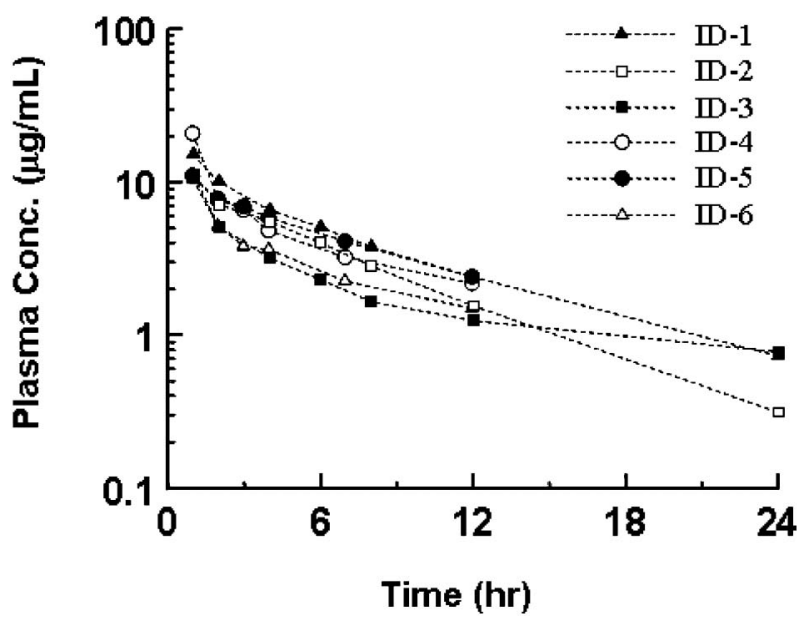

Fig. 1. Plasma Concentration-time Profiles of Doripenem Obtained for Each Patient

Symbols: $\mathbf{\Lambda}$, patient ID-1; $\square$, patient ID-2; $\mathbf{\square}$, patient ID-3; $\bigcirc$, patient ID-4; 0 , patient ID-5; $\triangle$, patient ID-6. Data from patients ID-1 and ID-2 were reported by our previous study. ${ }^{20}$ 

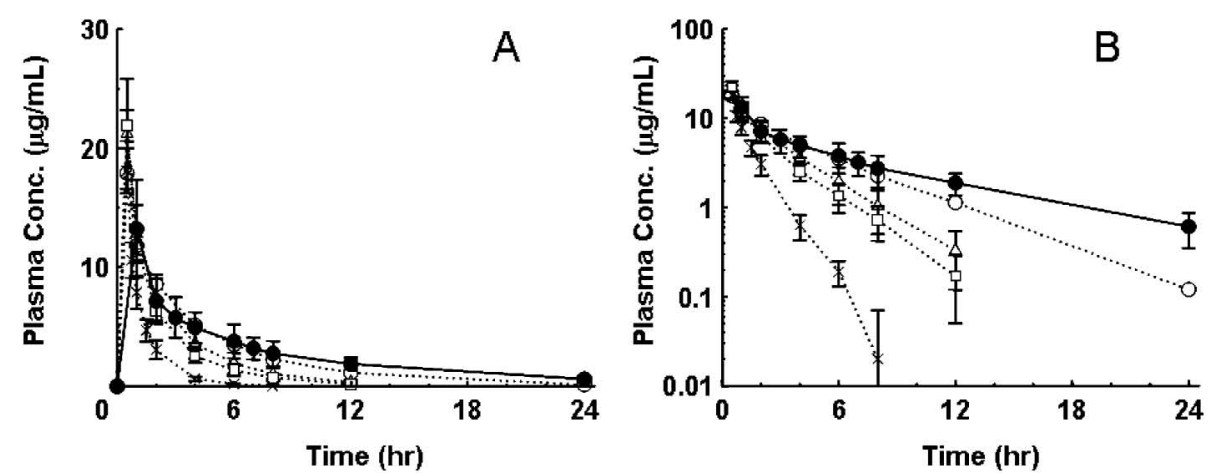

Fig. 2. Mean Plasma Concentration-versus-time Curves of Doripenem \pm standard deviation (S.D.) after a Single or First Dose of $250 \mathrm{mg}$ of Doripenem

Panel A shows the plasma concentration of doripenem on a linear scale, whereas panel B shows the plasma concentration of doripenem on a log scale. The closed circle,, depicts the plasma concentration of doripenem in the 6 patients (ID 1-6) receiving continuous hemodiafiltration (CHDF) in the current study. Other symbols depict data from a report by Uehara et al. ${ }^{10)} \mathrm{O}$, concentration of doripenem in plasma of patients $(n=2)$ with creatinine clearance $(\mathrm{Ccr})<30 \mathrm{ml} /$ $\min ; \triangle$, concentration of doripenem in plasma of patients $(n=6)$ with $C \mathrm{cr} 30-50 \mathrm{ml} / \mathrm{min}$; $\square$, concentration of doripenem in plasma of patients $(n=4)$ with Ccr $\geq$ $50 \mathrm{ml} / \mathrm{min}$; and $\times$, doripenem concentration of doripenem in plasma of patients $(n=6)$ with normal renal function.
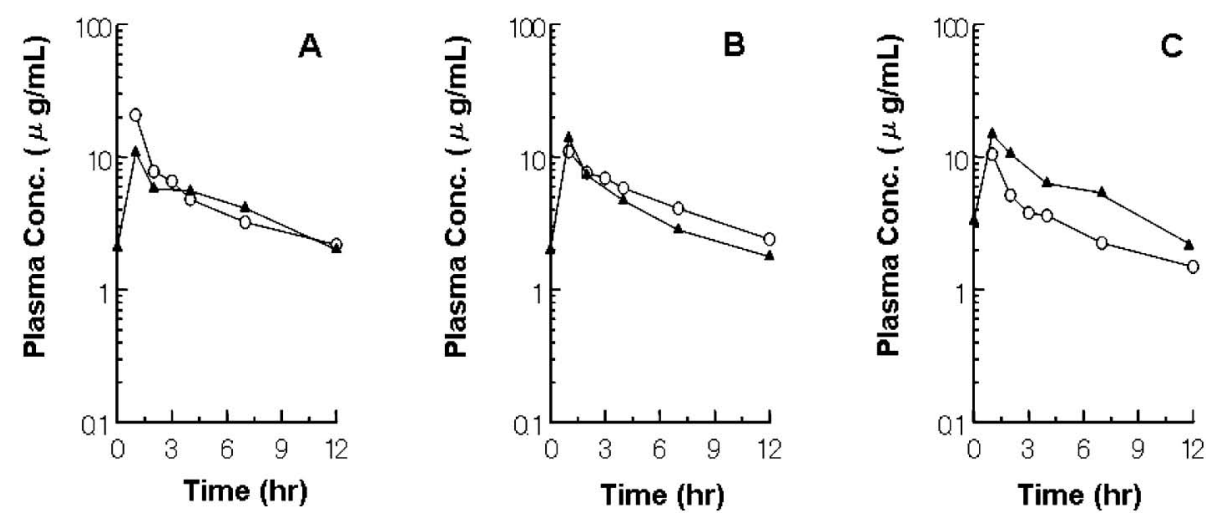

Fig. 3. Doripenem Concentration-time in 3 Patients (ID 4-6) Who Received an Intravenous Dose of 250 mg of Doripenem Every 12 Hours

Panel A represents data from patient ID-4; Panel B represents data from patient ID-5; and Panel C represents data from patient ID-6. Symbols: $\bigcirc$, initial dose of doripenem and $\boldsymbol{\Delta}$, subsequent 7 th dose of doripenem.

(on day 1) and subsequent 7 th doses (on day 4) in 3 patients (ID 4-6) in our study. After repeated dosing, plasma concentration profiles of doripenem (at steady state) in patients ID 4-6 were similar to the plasma concentration profile of doripenem after a 1st dose in all patients in our study, suggesting that little accumulation of doripenem occurred due to repeated dosing.

Pharmacokinetic (PK) Parameters Table 2 presents the PK parameters for doripenem, calculated from the plasma concentration data in patients receiving CHDF in the current study. The mean area under the curve extrapolated to infinity (AUC) was 74.6土 $15.6 \mathrm{mg} \cdot \mathrm{h} / \mathrm{l}$, the elimination half-life $\left(\mathrm{T}_{1 / 2}\right)$ was 7.9 $\pm 3.7 \mathrm{~h}$, the total doripenem clearance $\left(\mathrm{CL}_{\text {Total }}\right)$ was $58 \pm 12.7 \mathrm{ml} / \mathrm{min}$, and the doripenem clearance by
CHDF $\left(\mathrm{CL}_{\mathrm{CHDF}}\right)$ was $13.5 \pm 1.6 \mathrm{ml} / \mathrm{min}$.

In a previous clinical study of doripenem in patients $(n=2)$ with compromised renal function $\left.(\mathrm{Ccr}<30 \mathrm{ml} / \mathrm{min}),{ }^{10}\right)$ the AUC was $64.3 \mathrm{mg} \cdot \mathrm{h} / \mathrm{l}$, the $\mathrm{T}_{1 / 2}$ was $3.56 \mathrm{~h}$, and the $\mathrm{CL}_{\text {Total }}$ was $65 \mathrm{ml} / \mathrm{min}$. In contrast, in healthy adult volunteers, Uehara and colleagues reported an AUC of $20.3 \pm 3.5 \mathrm{mg} \cdot \mathrm{h} / 1$, a $\mathrm{T}_{1 / 2}$ of $0.9 \pm 0.1 \mathrm{~h}$, and a $\mathrm{CL}_{\text {Total }}$ of $209.8 \pm 29.5 \mathrm{ml} / \mathrm{min}$ (Table 3).

Our results, however, suggest that CHDF had little effect on the PK of doripenem. Because the duration of drip infusion differed between the two studies, it was not possible to make a direct comparison between the maximum concentration $\left(\mathrm{C}_{\max }\right)$ of doripenem in plasma of our patients and in the plasma of patients in the report by Uehara et al. 
Table 2. Pharmacokinetic Parameters after the First Dose of $250 \mathrm{mg}$ of Doripenem in Patients Receiving Continuous Hemodiafiltration $(\mathrm{CHDF})$

\begin{tabular}{|c|c|c|c|c|c|c|c|}
\hline Patient & $\begin{array}{c}\mathrm{C}_{\max }{ }^{a)} \\
(\mu \mathrm{g} / \mathrm{ml})\end{array}$ & $\begin{array}{l}\lambda_{\mathrm{z}}{ }^{b)} \\
\left(\mathrm{h}^{-1}\right)\end{array}$ & $\begin{array}{c}\mathrm{t}_{1 / 2}{ }^{c)} \\
(\mathrm{h})\end{array}$ & $\begin{array}{l}\mathrm{Vdss}^{d)} \\
(1)\end{array}$ & 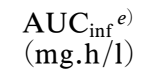 & $\begin{array}{l}\left.\mathrm{CL}_{\text {total }} f\right) \\
(\mathrm{ml} / \mathrm{min})\end{array}$ & $\begin{array}{l}\mathrm{CL}_{\mathrm{CHDF}^{g}}{ }^{2} \\
(\mathrm{ml} / \mathrm{min})\end{array}$ \\
\hline ID-1 & 15.2 & 0.102 & 6.8 & 21.3 & 95.8 & 43.5 & \\
\hline ID-2 & 10.8 & 0.136 & 5.1 & 24.7 & 65.5 & 63.7 & \\
\hline ID-3 & 11.1 & 0.045 & 15.3 & 62.9 & 66.4 & 62.8 & \\
\hline ID-4 & 20.8 & 0.097 & 7.2 & 24.3 & 85.6 & 48.7 & 13.5 \\
\hline ID-5 & 11.0 & 0.111 & 6.3 & 26.3 & 81.3 & 51.2 & 15.1 \\
\hline ID-6 & 10.5 & 0.108 & 6.4 & 38.5 & 53.2 & 78.3 & 12.0 \\
\hline Mean $\pm \mathrm{SD}^{h)}$ & $13.2 \pm 4.1$ & $0.10 \pm 0.03$ & $7.9 \pm 3.7$ & $33.0 \pm 15.8$ & $74.6 \pm 15.6$ & $58.0 \pm 12.7$ & $13.5 \pm 1.6$ \\
\hline
\end{tabular}

a) $\mathrm{C}_{\max }$ : maximum concentration of doripenem in plasma; $\left.b\right) \lambda_{\mathrm{z}}$ : elimination rate constant; $c$ ) $\mathrm{t}_{1 / 2}$ : elimination half-life; $d$ ) Vdss: volume of distribution at steady-state; e) $\mathrm{AUC}_{\mathrm{inf}}$ : area under the curve extrapolated to infinity; $\left.f\right) \mathrm{CL}_{\text {total }}$ : total doripenem clearance; $g$ ) $\mathrm{CL}_{\mathrm{CHDF}}$ : doripenem clearance by continuous hemodiafiltration $(\mathrm{CHDF}) ; h)$ SD: standard deviation. Data from patients ID-1 and ID-2 were reported by our previous study.20)

Table 3. Pharmacokinetic Parameters of Doripenem, according to Treatment and Level of Renal Function-Historical Comparison of Pharmacokinetic (PK) Parameters of Doripenem between Patients Receiving Continuous Hemodiafiltration (CHDF) and Individuals with Various Levels of Renal Function

\begin{tabular}{|c|c|c|c|c|c|c|}
\hline Type of individuals & $\begin{array}{l}\text { Duration (min) } \\
\text { of drip infusion }\end{array}$ & $\begin{array}{l}\left.\mathrm{C}_{\max } b\right) \\
(\mu \mathrm{g} / \mathrm{ml})\end{array}$ & $\begin{array}{l}\mathrm{AUC}^{\mathrm{c})} \\
(\mathrm{mg} \cdot \mathrm{h} / \mathrm{l})\end{array}$ & $\begin{array}{l}\mathrm{CL}_{\text {total }}{ }^{d)} \\
(\mathrm{ml} / \mathrm{min})\end{array}$ & $\begin{array}{l}\left.\mathrm{CL}_{\mathrm{CHDF}}{ }^{e}\right) \\
(\mathrm{ml} / \mathrm{min})\end{array}$ & $\begin{array}{c}\left.\mathrm{t}_{1 / 2} f\right) \\
(\mathrm{h})\end{array}$ \\
\hline CHDF patients $(n=6$, ID $1-6)$ & 60 & $13.2 \pm 4.1$ & $74.6 \pm 15.6$ & $58 \pm 12.7$ & $13.5 \pm 1.6$ & $7.9 \pm 3.7$ \\
\hline $\begin{array}{l}\text { Group I }(n=2)[10] \\
\left.\operatorname{Ccr}^{a}\right)<30 \mathrm{ml} / \mathrm{min}\end{array}$ & 30 & 17.9 & 64.3 & 65 & & 3.6 \\
\hline $\begin{array}{l}\text { Group II }(n=6)[10] \\
\mathrm{Ccr}^{a)} 30-50 \mathrm{ml} / \mathrm{min}\end{array}$ & 30 & $21.1 \pm 4.6$ & $48.2 \pm 13.4$ & $93 \pm 29.2$ & & $2.2 \pm 0.3$ \\
\hline $\begin{array}{l}\text { Group III }(n=4)[10] \\
\mathrm{Ccr}^{a)} \geqq 50 \mathrm{ml} / \mathrm{min}\end{array}$ & 30 & $21.9 \pm 1.3$ & $40.6 \pm 5.9$ & $104.3 \pm 15.2$ & & $2.0 \pm 0.4$ \\
\hline Healthy adults $(n=6)[10]$ & 30 & $18.1 \pm 1.9$ & $20.3 \pm 3.5$ & $209.8 \pm 29.5$ & & $0.9 \pm 0.1$ \\
\hline
\end{tabular}

Data are expressed as the mean \pm standard deviation (S.D.), when the number of patients or individuals is more than 2. Data from patients, ID 1-6, who received CHDF are from the current study. Data from patients in Group I, II, and III and healthy adults were previously reported by Uehara et al. ${ }^{10)} a$ ) Ccr: creatinine clearance; $b) \mathrm{C}_{\max }$ : maximum concentration of doripenem in plasma; $c$ ) $\mathrm{AUC}_{\mathrm{inf}}$ : area under the curve extrapolated to infinity; $d$ ) $\mathrm{CL}_{\text {total }}$ : total doripenem clearance; $e$ ) $\mathrm{CL}_{\mathrm{CHDF}}$ : doripenem clearance by $\left.\mathrm{CHDF} ; f\right) \mathrm{t}_{1 / 2}$ : elimination half-life.

Safety In the current study, no adverse effects of doripenem and no clinically significant change in any laboratory parameter due to doripenem administration were observed.

\section{DISCUSSION}

Recently, appropriate empiric use of antimicrobial agents in the early phase of treatment has been recommended. ${ }^{11)}$ For managing severe infections in patients in the ICU, antimicrobial agents in the carbapenem family are quite useful. Doripenem, a new antimicrobial agent in the carbapenem family, has a broad antibacterial spectrum of excellent activity against aerobic and anaerobic Gram-positive and Gram-negative bacteria. For example, the activity of doripenem against Pseudomonas aeruginosa is higher than that of any other carbapenem. ${ }^{12,13)}$ Furthermore, doripenem is unlikely to cause adverse reac- tions such as convulsions in the central nervous system. ${ }^{14)}$ Thus, doripenem is expected to improve the overall outcome of clinical treatment of severe bacterial infections.

Given that doripenem is a new antibiotic, we collected PK data in patients undergoing CHDF in a previous pilot study; however, only limited data could be obtained due to the small sample size. ${ }^{20)}$ Furthermore, the study involved a single dose of doripenem. Thus, the recommended dose level of doripenem could not be established for patients undergoing CHDF. According to pharmacokinetics (PK)/pharmacodynamics $(\mathrm{PD})$ theory, the time above the minimum inhibitory concentration (MIC) needs to be at least $40-50 \%$ of the dosing interval, in order to achieve optimal efficiency of treatment with carbapenems. ${ }^{15}$

Inadequate dose levels of antibiotics can lead to de- 
velopment of bacterial resistance to drugs and poor prognosis for the patient. If removal of an antibiotic in the bloodstream by CHDF is markedly higher, then dosage supplementation may be necessary to ensure therapeutic efficacy of an antibiotic. Therefore, it is desirable to determine recommended dose levels of antibiotics in patients receiving CHDF. In light of the recent sharp increase in the number of patients receiving CHDF in ICUs, we examined the PK of doripenem in patients receiving CHDF.

Doripenem, which has a molecular weight (MW) of 438 daltons and a protein-binding ratio (PBR) of 6 $-9 \%$, is excreted primarily in an unchanged form via the kidneys, with a urinary excretion ratio of $75 \% .{ }^{16)}$ Usually, on the basis of creatinine clearances, it is possible to determine the theoretical dose level for drugs primarily excreted via the kidneys. ${ }^{17)}$ However, in patients undergoing CHDF, drug PK can change markedly, due to elimination of drugs by filtration and dialysis. For this reason, it is difficult to determine appropriate dose levels of drugs for patients undergoing CHDF. Major factors known to affect elimination of drugs by CHDF include properties (pore size, membrane area, membrane material, adsorptive potential, and electric charge) of the dialyzer, physicochemical characteristics (molecular weight, protein binding rate, distribution volume, water solubility, and molecular electric charge) of the drugs, and methods of CHDF utilized. ${ }^{18)}$

Because doripenem has a low molecular weight and low protein binding, we expected that a high percentage of doripenem in the bloodstream of patients in the present study would be eliminated by CHDF. In the 6 patients with acute kidney injury (mean $\mathrm{Ccr}=$ $9.02 \mathrm{ml} / \mathrm{min}$ ) who underwent CHDF in our study, analysis of $\mathrm{PK}$ parameters $\left(\mathrm{a} \mathrm{T}_{1 / 2}\right.$ of $7.9 \mathrm{~h}, \mathrm{a} \mathrm{CL}_{\text {total }}$ of $58 \mathrm{ml} / \mathrm{min}$, and a $\mathrm{CL}_{\mathrm{CHDF}}$ of $13.5 \mathrm{ml} / \mathrm{min}$ ) suggested that CHDF had relatively little effect on clearance of doripenem, as compared with results of a previous clinical study in untreated, normal subjects (yielding a $\mathrm{T}_{1 / 2}$ of $0.9 \mathrm{~h}$, and a $\mathrm{CL}_{\text {total }}$ of $210 \mathrm{ml} / \mathrm{min}$ ) reported by Uehara et al. ${ }^{10)}$

HEMOFEEL ${ }^{\otimes} \mathrm{SH}-1.0$, used in the present study, is known to lack adsorptive potential. However, this polysulfone membrane, with a $50 \%$ sieving coefficient (SC) corresponding to a molecular weight of about 30000 daltons, is designed to have a relatively large pore size. Because doripenem has low molecular weight and low protein binding $(<10 \%)$, its SC is nearly 1.0 , suggesting the possibility of elimination of a high percentage of the administered dose. For this reason, the methods of CHDF utilized appeared to have markedly affected the results of our study.

Several past studies indicated that meropenem, an antibiotic of the carbapenem family, has a low molecular weight (MW, 438 daltons) and low protein-binding rate (PBR, 2\%) like doripenem. However, when the filtration flow rate $\left(\mathrm{Q}_{\mathrm{F}}\right)$ was set at $3000 \mathrm{ml} / \mathrm{h}$ during CHDF, hemofiltration clearance was $49.7 \pm 8.3 \mathrm{ml} / \mathrm{min} .^{5)}$ Hemofiltration clearance of panipenem (MW, 339 daltons; PBR, 7\%) was 31.9土 $2.1 \mathrm{ml} / \mathrm{min}$ with the following CHDF conditions: $\mathrm{Q}_{\mathrm{D}}$, $1000 \mathrm{ml} / \mathrm{h}$ and $\mathrm{Q}_{\mathrm{F}}, 1000 \mathrm{ml} / \mathrm{h} .{ }^{7)}$ Furthermore, vancomycin (MW, 1,448 daltons; PBR, 55\%) has a higher PBR and MW compared to other carbapenem family antibiotics. However, $\mathrm{CL}_{\mathrm{CHDF}}$ of vancomycin was $30 \pm 6.7 \mathrm{ml} / \mathrm{min}$ with the following CHDF conditions: $\mathrm{Q}_{\mathrm{D}}, 1000 \mathrm{ml} / \mathrm{h}$ and $\mathrm{Q}_{\mathrm{F}}, 2000 \mathrm{ml} / \mathrm{h}{ }^{6}{ }^{6}$ This suggests that $\mathrm{CL}_{\mathrm{CHDF}}$ of vancomycin exceeds that of doripenem $\left(\mathrm{CL}_{\mathrm{CHDF}}, 13.5 \pm 1.6 \mathrm{ml} / \mathrm{min}\right)$.

Thus, a potential theoretical limitation of interpretation of our study is the efficiency of the CHDF system in its elimination of a substantial amount of doripenem. In the present study, CHDF was carried out at $500 \mathrm{ml} / \mathrm{h}$ dialysate fluid and $300 \mathrm{ml} / \mathrm{h}$ substitution fluid. The assumed creatinine clearance in this setting is nearly $13 \mathrm{ml} / \mathrm{min}$.

Because the maximum volume of Sublood-BS ${ }^{\circledR}$ (a dialysate and substitution fluid) covered by health insurance in Oita Prefecture of Japan is $20 \mathrm{l}$ /day (approximately $800 \mathrm{ml} / \mathrm{h}$ ), and the efficiency of removal of low-molecular-weight substances such as blood urea nitrogen and creatinine does not differ between filtration and dialysis, and filter life becomes shorter if $Q_{F}$ is increased, we set $Q_{D}$ at $500 \mathrm{ml} / \mathrm{h}$ and $Q_{F}$ at 300 $\mathrm{ml}\left(\mathrm{Q}_{\mathrm{D}}>\mathrm{Q}_{\mathrm{F}}\right)$. This CHDF method is used routinely in our facility.

However, following the recent report that hemodynamics and prognosis can be improved by increasing the hemopurification level in ICU patients complicated by acute kidney injury, ${ }^{19)}$ hemopurification under the setting we utilized can no longer be considered to achieve a satisfactory outcome. Ronco et al. ${ }^{19)}$ proposed high-volume hemofiltration (HVHF) to increase amounts of various solutes (from low-molecular-weight to intermediate-molecular-weight substances). Because doripenem has a low molecular weight and low protein binding, the 
amount of elimination of doripenem likely will increase as the hemopurification rate increases. Thus, the dose level of doripenem probably will need to be increased when the antibiotic is used in patients undergoing HVHF. Therefore, determining the appropriate dose level of doripenem in patients undergoing HVHF requires future study.

When using doripenem in patients with compromised renal function, it should be noted that the package insert states that doripenem should be used once or twice daily at a dose level of $0.25 \mathrm{~g}$ for patients with a $\mathrm{Ccr}<30 \mathrm{ml} / \mathrm{min}$. We found no need to increase the dosage of doripenem when the antibiotic was used in patients undergoing CHDF under the settings tested in our past ${ }^{20}$ and present study. For patients with residual renal function equivalent to a $\mathrm{Ccr}<30 \mathrm{ml} / \mathrm{min}$, the upper limit of dose level is 250 $\mathrm{mg}$ of doripenem administered twice daily. Plasma concentrations of doripenem after a single or first dose of $250 \mathrm{mg}$ of doripenem were $2.29-5.09 \mu \mathrm{g} / \mathrm{ml}$ at $6 \mathrm{~h}$ (in patients ID 1-3) and $2.25-4.10 \mu \mathrm{g} / \mathrm{ml}$ at $7 \mathrm{~h}$ (in patients ID 4-6), respectively. These findings suggest that $250 \mathrm{mg}$ of doripenem administered every 12 hours provided more than $50 \%$ of $\mathrm{T}>\mathrm{MIC}$ against bacteria, assuming with a MIC of less than $2 \mu \mathrm{g} / \mathrm{ml}$ of doripenem.

This study has several limitations. First, we only examined a small number of patients (6 total). In addition, the historical comparison was made between two different small studies which included groups of patients with varying degrees of renal impairment as well as healthy volunteers. Caveats for comparisons between separate studies should be noted in detail. In the current study, we used a polysulfone hemofilter with a membrane surface area of $1.0 \mathrm{~m}^{2}$ (HEMOFEEL ${ }^{\circledR} \mathrm{SH}-1.0$, Toray Medical, Inc., Japan). However, other hemofilters and CHDF conditions were not tested, and different conditions may require different doripenem concentrations. Future studies should focus on determining doripenem concentrations that are needed for various conditions.

In conclusion, our results show that CHDF under the conditions tested appeared to have little effect on the clearance of doripenem. Therefore, the level of doripenem in plasma of patients undergoing CHDF can be controlled satisfactorily by adjusting the dose and dosing interval of doripenem, in accordance with the patient's residual renal function. In the present study, a dose of $250 \mathrm{mg}$ of doripenem administered intravenously every $12 \mathrm{~h}$ provided adequate plasma concentrations of doripenem upon steady state, without drug accumulation. As the influence of CHDF on the PK of doripenem is suspected to depend on $\mathrm{Q}_{\mathrm{D}}$ and $\mathrm{Q}_{\mathrm{F}}$, however, we currently are performing a study of the $\mathrm{PK}$ of doripenem during HVHF.

\section{REFERENCES}

1) Murray P., Hall J., Am. J. Respir. Crit. Care Med., 162, 777-781 (2000).

2) Sadahiro T., Hirasawa H., Oda S., Shiga H., Nakanishi K., Kitamura N., Hirano T., Crit. Care Med., 29, 1386-1392 (2001).

3) Jiang H. L., Xue W. J., Li D. Q., Yin A. P., Xin X., Li C. M., Gao J. L., World J. Gastroenterol., 11, 4815-4821 (2005).

4) Page B., Vieillard-Baron A., Chergui K., Peyrouset O., Rabiller A., Beauchet A., Aegerter P., Jardin F., Crit. Care, 9, R755-R763 (2005)

5) Thalhammer F., Schenk P., Burgmann H., El Menyawi I., Hollenstein U. M., Rosenkranz A. R., Sunder-Plassmann G., Breyer S., Ratheiser K., Antimicrob. Agents Chemother., 42, 2417-2420 (1998).

6) DelDot M. E., Lipman J., Tett S. E., Br. J. Clin. Pharmacol., 58, 259-268 (2004).

7) Hayakawa M., Ito Y., Fujita I., Iseki K., Gando S., ASAIO J., 52, 398-403 (2006).

8) Griffith D. E., Aksamit T., Brown-Elliott B. A., Catanzaro A., Daley C., Gordin F., Holland S. M., Horsburgh R., Huitt G., Iademarco M. F., Iseman M., Olivier K., Ruoss S., von Reyn C. F., Wallace R. J. Jr., Winthrop K., Am. J. Respir. Crit. Care Med., 175, 367-416 (2007).

9) Kishino S., Takekuma Y., Sugawara M. Shimamura T., Furukawa H., Todo S., Miyazaki K., J. Chromatogr. B Analyt. Technol. Biomed. Life Sci., 780, 289-294 (2002).

10) Uehara S., Murao W., Seno Y., Andoh E., Monden K., Kariyama R., Tsugawa M., Nakashima M., Kumon H., Jpn. J. Chemother. 53, 130-135 (2005).

11) Bochud P. Y., Bonten M., Marchetti O., Calandra T., Crit. Care Med., 32, S495-512 (2004)

12) Tsuji M., Ishii Y., Ohno A., Miyazaki S., 
Yamaguchi K., Antimicrob. Agents Chemother., 42, 94-99 (1998).

13) Sakyo S., Tomita H., Tanimoto K., Fujimoto S., Ike Y., J. Antibiot., 59, 220-228 (2006).

14) Horiuchi M., Kimura M., Tokumura M., Hasebe N., Arai T., Abe K., Toxicology, 222, 114 (2006).

15) Keil S., Wiedemann B., Antimicrob. Agents Chemother., 41, 1215-1219 (1997).

16) Nakajima M., Oguma T., Jpn. J. Chemother., 53, S104-123 (2005).
17) Iga T., Medical Practice, 19, 244-248 (2002).

18) Cotterill S., J. Antimicrob. Chemother., 36, 773-780 (1995).

19) Ronco C., Bellomo R., Homel P., Brendolan A., Dan M., Piccinni P., La Greca G., Lancet, 356, 26-30 (2000).

20) Hidaka S., Goto K., Matsumoto S., Oyama T., Yamamoto S., Yasuda N., Hagiwara S., Shingu C., Iwasaka H., Noguchi T., Rinsho to Biseibutsu, 35, 199-203 (2008). 